\title{
USING NITRATE, CHLORIDE, SODIUM, AND SULFATE TO CALCULATE GROUNDWATER AGE
}

\author{
Kimm Crawford \\ Crawford Environmental Services, 44918 W Pelican Drive, Watertown, SD 57201,USA, kcraw@itctel.com
}

Terry Lee

Olmsted County Environmental Resources Department, 2122 Campus Drive SE, Rochester, MN 55904, USA, lee. terry@co.olmsted.mn.us

\begin{abstract}
Regression analysis is used to identify monotonic trends to assign water age using ion data from two large well water databases from southeast Minnesota (SE MN). Nitrate $\left(\mathrm{NO}_{3}-\mathrm{N}\right)$, chloride $(\mathrm{Cl})$, sodium $(\mathrm{Na})$, and sulfate $\left(\mathrm{SO}_{4}\right)$ ions in the commonly used aquifers in SE MN can be used as groundwater tracers since they are either entirely or partly anthropogenic in their sources, their loading occurs on a regional scale, and they are almost entirely conserved.
\end{abstract}

Ion concentrations over time are used to establish six trend patterns. Two patterns are unchanging (background and stable above background), and four are changing (linear up, exponential up, peaking, and down). These patterns are then used to assign specific age values or age ranges to the well based upon that ion. For ions with linear upward trends, specific ages are derived from the "Intercept Year" representing a time when water extracted from the well first infiltrated from the land surface containing the ion at detectable concentrations and the "Marker-Year" representing the beginning of large scale trend changes for that ion source.

\section{Introduction}

Public agencies have collected large amounts of environmental data in recent times as part of numerous programs some have limited purposes and time frames, others are broader and open ended. Data analysis for groundwater quality has often been limited to defining what is in the drinking water today.

This work relates trends in water ion concentrations over time to decadal changes in ion loading sources to estimate the "age of water" now extracted from wells. It varies from traditional groundwater age dating in that it relies on changing patterns in the regional or national scale related to continuous loadings. This contrasts with introduced chemical or isotopic markers, which generally have specific release events or time periods. In addition, this method relies on commonly monitored analytes from already available sources.
Data from two databases is used to look at statistical trends in groundwater quality from residential wells over time. First is the Southeast Minnesota Water Analysis Lab (SEMWAL) database that provides data from Olmsted County from 1970-2014 (SEMWAL, 2015). Much of the data in the SEMWAL database results from required testing during property transactions. Over 50,000 samples have been processed by the lab, 19,337 of which are for private wells in Olmsted County including 7,048 distinct addresses. An attempt is made to assign addresses to specific wells. Where five or more years of data is available, trend analysis is done for that address -- 590 for $\mathrm{NO}_{3}, 446$ for $\mathrm{Cl}$, and 430 for $\mathrm{SO}_{4}$. The monitoring period record varies significantly by well.

The second database used for this analysis is the Dakota County Ambient Groundwater Quality Study (AGQS), which has sampled from 24-80 wells annually since 1999 (AGQS, 2015). Wells were chosen to reflect both geographic and aquifer differences in the county. The goal was to determine baseline water chemistry, characterize the occurrence of anthropogenic compounds, conduct trend analyses, and identify land use factors influencing the three most heavily used drinking water aquifers in the County. The database includes seventy six (76) wells that have been sampled up to 13 times each since 1999.

\section{Anthropogenic Sources and Background Concentrations}

Nitrate $\left(\mathrm{NO}_{3}-\mathrm{N}\right)$, chloride $(\mathrm{Cl})$, and sulfate $\left(\mathrm{SO}_{4}\right)$ are highly mobile in groundwater in SE MN. The first two are mainly attributable to anthropogenic sources while $\mathrm{SO}_{4}$ has a natural component. A 1994 tritium study of 67 private wells in Olmsted County found that $\mathrm{NO}_{3}-\mathrm{N}$, $\mathrm{Cl}$, and $\mathrm{SO}_{4}$ were lowest in vintage water $(<1953)$ and highest in recent water $(>1953)$. Nearly all vintage age water had no detectable $\mathrm{NO}_{3}-\mathrm{N}$ or $\mathrm{Cl}$.

\section{Nitrate and Chloride}

Background or natural concentrations for $\mathrm{NO}_{3}-\mathrm{N}$ and $\mathrm{Cl}$ in SE MN groundwater used for domestic drinking wa- 
ter are generally at or below detection limits of common analytical methods: $\mathrm{NO}_{3}-\mathrm{N}<0.2 \mathrm{mg} / 1$ and $\mathrm{Cl}<0.5 \mathrm{mg} / \mathrm{l}$. Of the more than 7,000 wells in Olmsted County tested since $1970,62 \%$ have no detectable $\mathrm{NO}_{3}-\mathrm{N}$ and $33 \%$ have no detectable $\mathrm{Cl}$. Dakota County data has a slightly lower percentage of non-detects for $\mathrm{NO}_{3}-\mathrm{N}(46 \%)$ and $\mathrm{Cl}$ (22\%) (SEMWAL, 2015, AGQS County, 2015).

Nitrate is largely attributed to agriculture, directly in the form of applied inorganic nitrogen fertilizers or indirectly in the form of animal manures (MDA, 2013, MPCA, 2013, USDA, 2014). Agricultural crops are exported from the local area, while manure is "recycled". Nitrogen from fertilizer and from manure not taken up and then removed with harvested crops, stored in organic matter, or not denitrified moves into and through soils with infiltrating water and is eventually converted to nitrate in soils or groundwater.

Once $\mathrm{NO}_{3}-\mathrm{N}$ and $\mathrm{Cl}$ pass below the vadose zone of soils, the ions remain largely unchanged. In the case of $\mathrm{NO}_{3}-\mathrm{N}$, it is possible that some conversion to gaseous nitrogen occurs by the process of denitrification. This process is mostly limited to the soil zone, and an organic carbon or other reducing substance such as ferrous iron is needed for denitrification (Green, 2010). $\mathrm{NO}_{3}-\mathrm{N}$ and $\mathrm{Cl}$ are generally conserved in SE MN groundwater aquifers used for residential water supply.

The chloride component of potassium-based fertilizers $(\mathrm{KCl})$, like nitrate, moves with infiltrating water. The potassium is either removed with crops or tightly held in the clay minerals of soils. The chloride from fertilizer and the nitrogen not removed by crops infiltrate to groundwater in similar loading rates (AGQS, 2013).

Chloride also originates from salt applied to roads in winter for deicing, brine applied for dust control in summer, as a byproduct of water softening, and infiltration from septic systems (MNDOT, 2014). The non-agricultural sources for chloride are mostly in the form of common salt (sodium chloride), which also contributes anthropogenic sodium (Na) to groundwater. Anthropogenic $\mathrm{Cl}$ loading is large relative to the amount retained in biological systems. Additionally, chloride forms no common insoluble salts and therefore moves freely through soil and groundwater systems.

Fertilizer use in Minnesota increased substantially from 1940 to 1955 and then about doubled in the following five years (Dahl, 1970). By 1964, nitrogen use was 20\% of today's rate and potash about $30 \%$ (USDA NASS).
Regression analysis was used to establish Marker-Years used in this study to represent the first large scale change in fertilizer source loads. Minnesota use statistics yielded a Marker-Year for nitrogen of 1962 and potash 1960. National use statistics yielded Marker-Years of 1955 for nitrogen and 1948 for potash (USDA NASS). Not enough county specific data is available to calculate Marker-Years.

Salt use increased dramatically between 1960 and 1970, declined during the 1970s, and has been generally increasing since the 1980s. There is substantial annual variation in road salt use. The Marker-Year for salt based on MNDOT data is 1959 (MNDOT, 2014, UMN, 2008), and the Marker-Year based on national statistics for total salt use is 1955 (Kelly, 2013). Figure 1 illustrates the ion source use changes and Table 1 summarizes the Marker-Years used in calculating water age for those sources.

\section{Sodium}

Sodium from road salt and softener salt is partially retained by clay minerals through ion-exchange reactions and is not delivered to groundwater as completely as are chloride and nitrate. Sodium has a natural background in groundwater from geologic weathering processes. Sodium in the absence of chloride in well water is one basis for defining the natural background. Sodium is highly correlated with chloride, and regression of $\mathrm{Cl}$ and $\mathrm{Na}$ yields a background of about $4 \mathrm{mg} / \mathrm{l}$ when $\mathrm{Cl}$ is not detected. The correlation also indicates that sodium has a lower molar concentration than chloride due to its retention by soils and due to a portion of the $\mathrm{Cl}$ originating from potash fertilizer $(\mathrm{KCl})$. Sodium to chloride $(\mathrm{Na}: \mathrm{Cl})$ ratios reflect the proportion of $\mathrm{Cl}$ from agriculture versus road salt or softener salt (AGQS, 2015).

\section{Sulfate}

Background or natural concentrations of sulfate may be derived from gypsum in limestone and sandstone and from the weathering of iron pyrite $\left(\mathrm{FeS}_{2}\right)$ in shales (Robertson, 1989). Sulfate is also contributed by atmospheric deposition from the combustion of fossil fuels. By the mid 1970s, the implementation of the Clean Air Act reversed the rapid increase in Sulfur Dioxide $\left(\mathrm{SO}_{2}\right)$ emissions that had begun in the late 1950s. The downward trend in $\mathrm{SO}_{2}$ emissions continues (Smith 2004, Smith, 2011). The National Atmospheric Deposition Program (NADP) monitoring data confirm the decline in deposition in the Midwest. A regression analysis of national $\mathrm{SO}_{2}$ emissions data identifies a peak in 1970 . 


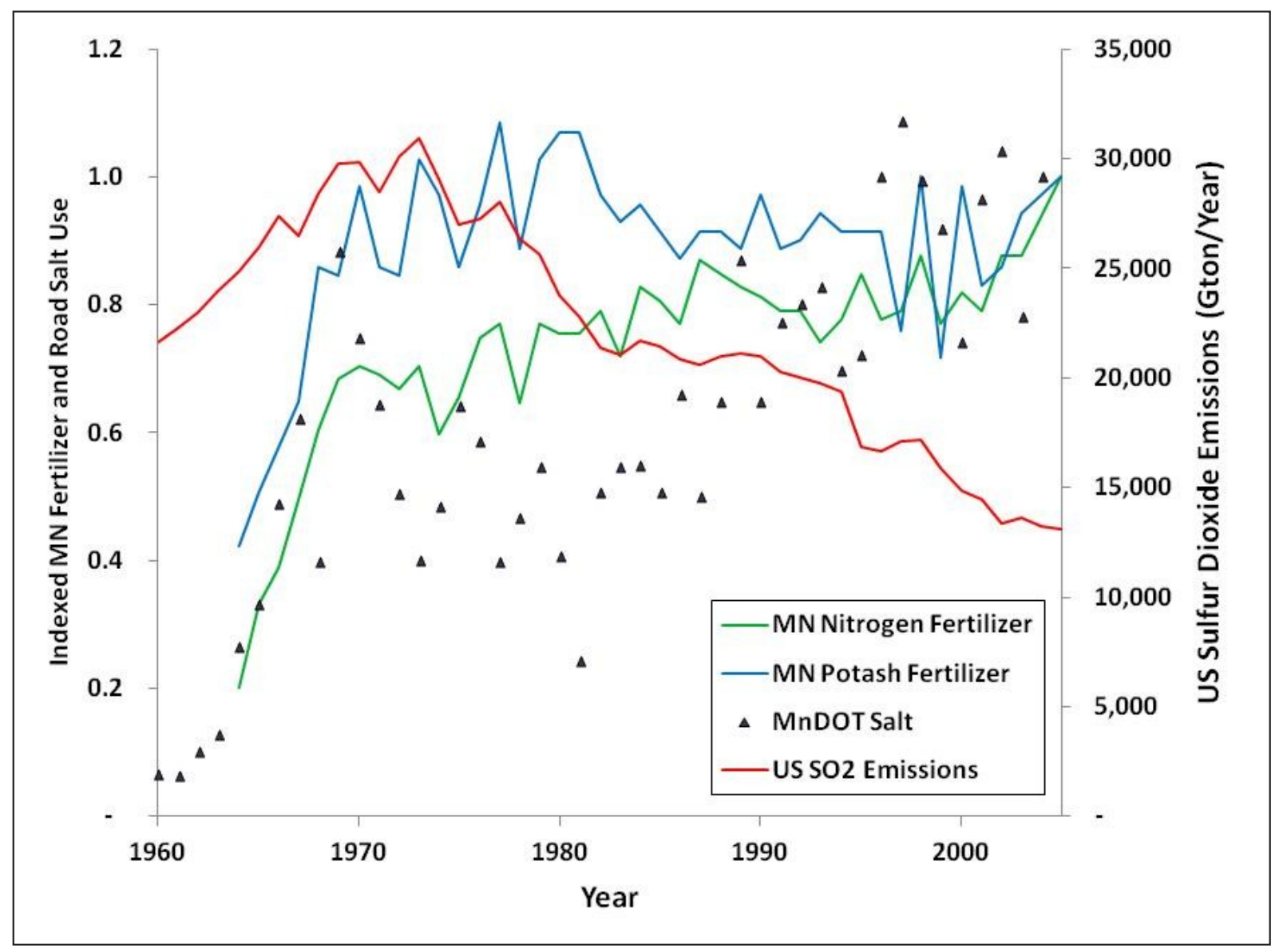

Figure 1. Fertilizer and Salt Use Indexed to 2005 and Reported National $\mathrm{SO}_{2}$ Emissions.

\begin{tabular}{|l|c|c|}
\hline \multirow{2}{*}{\multicolumn{1}{|c|}{ Ion Loading Source }} & \multicolumn{2}{c|}{$\begin{array}{c}\text { Marker-Year by } \\
\text { Data Source }\end{array}$} \\
\cline { 2 - 3 } & Mimnesota & US \\
\hline Nitrogen Fertilizer & 1962 & 1953 \\
\hline Potash Fertizer (KCl) & & 1951 \\
\hline Road Salt (NaCl) & 1959 & \\
\hline Total Salt Use (NaCl) & & 1955 \\
\hline
\end{tabular}

Table 1. Marker-Years for lon Source Loadings.

Sulfate moves relatively freely with infiltrating water in the SE MN groundwater environment. Common salts of $\mathrm{SO}_{4}$ are generally soluble in the range of concentrations found in SE MN, and redox conditions for converting $\mathrm{SO}_{4}$ to sulfur or hydrogen sulfide exist only in very deep groundwater not ordinarily used for domestic purposes (USGS, 2009). Sulfate, like $\mathrm{NO}_{3}-\mathrm{N}$ is involved in biological processes and can be temporarily retained in soils or biological materials. The many $\mathrm{SO}_{4}$ trends found during this study illustrates the ion's mobility.

\section{Method}

Statistical analysis using Kendal-Thiel (KT) nonparametric regression is employed to identify monotonic trends - not necessarily linear (Helsel, 2002, Helsel, 2012). At least 5 samples in separate years are needed to detect trends at the minimum $90 \%$ statistical significance level accepted for this work. Of the approximately 7,000 wells in the Olmsted dataset approximately $10 \%$ meet the criterion for $\mathrm{NO}_{3}-\mathrm{N}$ while only $8 \%$ meet that criterion for $\mathrm{Cl}$ and $\mathrm{SO}_{4}$. This reflects the longer period of record for $\mathrm{NO}_{3}-\mathrm{N}(1970-2014)$ than $\mathrm{Cl}$ and $\mathrm{SO}_{4}(1988-$ 2014).

The choice of significance level could, in principle, affect whether a well is identified as trending or not. For the wells in the two datasets analyzed, all but a few, which show $90 \%$ significance also show $95 \%$ or greater significance. Where the trend pattern is significant but 
not necessarily linear, quadratic regression is tested to see if the well is peaking or leveling off. Wells without a trend were categorized as background or stable above background based on $\mathrm{NO}_{3}-\mathrm{N}$ and $\mathrm{Cl}$ values. This analysis produced the six types of statistically trending patterns discussed below.

For the upward trend pattern wells, the KT regression yields an "Intercept-Year". The Intercept-Year is a time when the water now extracted from the well first infiltrated from the land surface. The Intercept-Year is a reference marker for each ion, which represents the lag time or age of the water relative to the Marker-Year for the specific ion source. This provides a specific numerical estimate of the water age.

The calculated Intercept-Year is valid only for the "c" portion of the logistic curve which is assumed to have a minimum slope of $3 \%$. This rate reflects the large loading increases beginning in the 1950s. Lesser relative slopes are assumed to be in the " $b$ " and " $d$ " portions of the logistic curve and can't be used to calculate an appropriate Intercept-Year.
The other five trend categories do provide a range of upper and/or lower limits to the age of the water in the well but no Intercept-Year can be calculated from those trends.

\section{Trend Patterns for Groundwater Ion Con- centrations}

Figure 1 is an example of a long-term ion $\left(\mathrm{NO}_{3}-\mathrm{N}\right)$ pattern in a well, which is represented mathematically as a logistic (sinusoidal) curve. We expect that any well experiencing a change in an ion loading from surface sources would have an upward trend curve similar to that shown in Figure 2 or its mirror image if a downward trend.

The logistic curve contains five distinct trend patterns (a-e in Figure 2). In the earliest period "a", the ion is stable at background concentrations, followed by periods of rapid increase "c" and then a relative stable period at higher concentrations "e". The transition at " $b$ " represents an exponential increase which is modeled as a quadratic curve. The transition at " $\mathrm{d}$ " is also modeled as a quadratic curve and represents a peak or leveling off.

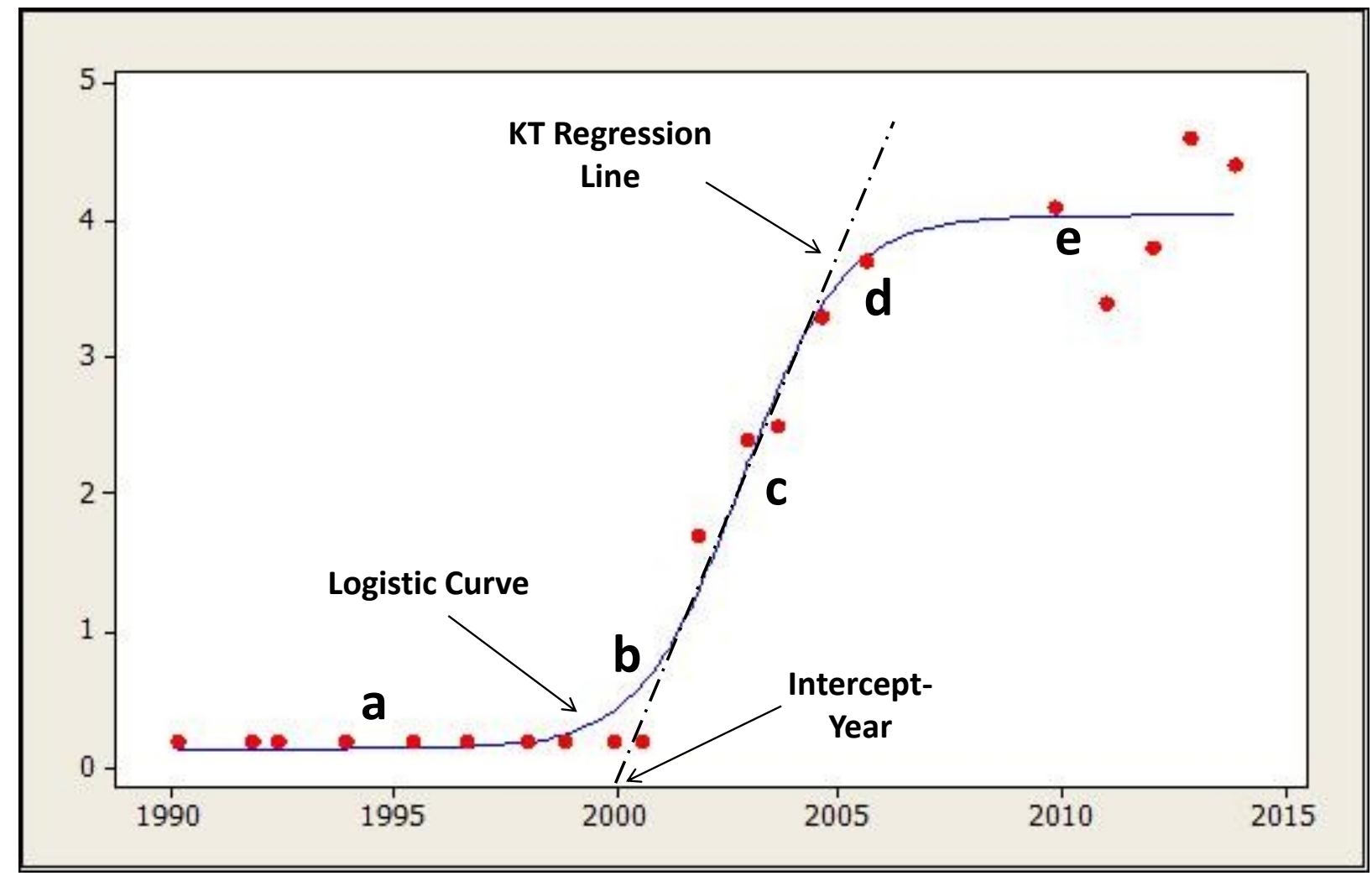

Figure 2. Logistic Curve Model Applied to $\mathrm{NO}_{3}$ in Well 11323 from Olmsted County. a-Background Non-Detect (ND), b-Exponential Up (Quad+), c-Linear Up (UP), d-Peaking (Quad-), e-Stable Above Background - No Trend (NT) 
The other pattern identified in this work is a decreasing pattern, which is a mirror image of that in Figure 2.

The five trend patterns in the logistic curve can be grouped in two categories: unchanging (background, and stable above background), and changing (exponential up, linear up, and peaking). The sixth trend pattern represented by the exponential downward pattern is also in the changing category (Figure 6).

All of the patterns and transitions represented by Figure 2 and its mirror image are seen in the well monitoring records. The statistical analysis is the basis for classifying well by trend pattern. In most cases the monitoring period contains only a portion of the logistic curve. Few wells in the dataset show the complete logistic curve primarily because of the short period of monitoring record and infrequency of monitoring.

The graph of Well 11323 illustrates a logistic curve for $\mathrm{Cl}$ and its mirror image for $\mathrm{SO}_{4}$. Figures 3 through 5 show a side-by-side comparison of the respective ion sources and ion trends in the well. The well ion concentrations reflect the trend patterns in the respective ion sources. In this particular well, the lag time between the ion source loading (Marker-Year) and well ion concentrations (In-
tercept-Year) is approximately 40 years. The lag time is similar for all three ions.

Well 11323 illustrates that a long record is necessary to be able to see all or most of the logistic curve. In addition, the period of record would also have to reflect the lag time (water age) for the well.

The Intercept-Year from the linear portion of the logistic curve is not the exact asymptotic intercept year. As can be seen in the example in Figure 1, the linear intercept year can vary slightly from the asymptotic year. In the logistic model, the initial increase is exponential and not linear as is assumed with the linear trend regression.

Figure 6 illustrates a portion of the mirror image of Figure 2, the downward trend portion of the logistic curve. In well 695881, the trend would be statistically modeled as a quadratic or exponential. This downward trend correlates with a reduction in $\mathrm{NO}_{3}-\mathrm{N}$ loading consistent with the area's conversion from agriculture to mixed residential in the early 1990s.

\section{Ion Trends for Olmsted County Wells}

Table 2 summarizes the six trend categories for the subset of the Olmsted County data that meet the 5-year criterion. More non-detects are seen with $\mathrm{NO}_{3}-\mathrm{N}(>50 \%)$

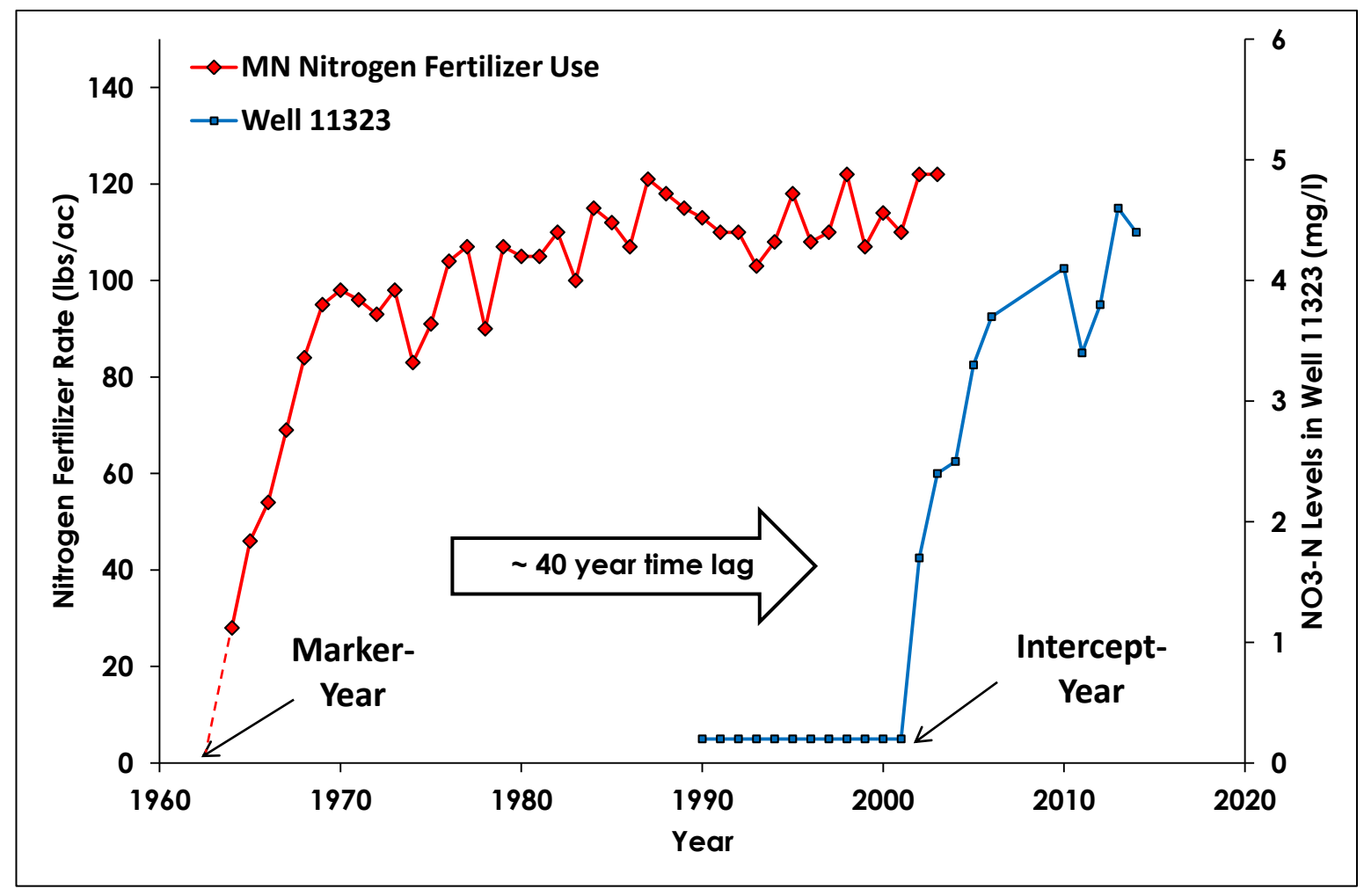

Figure 3. Minnesota Nitrogen Fertilizer Use Trends and the Nitrate Concentrations in Well 11323. 


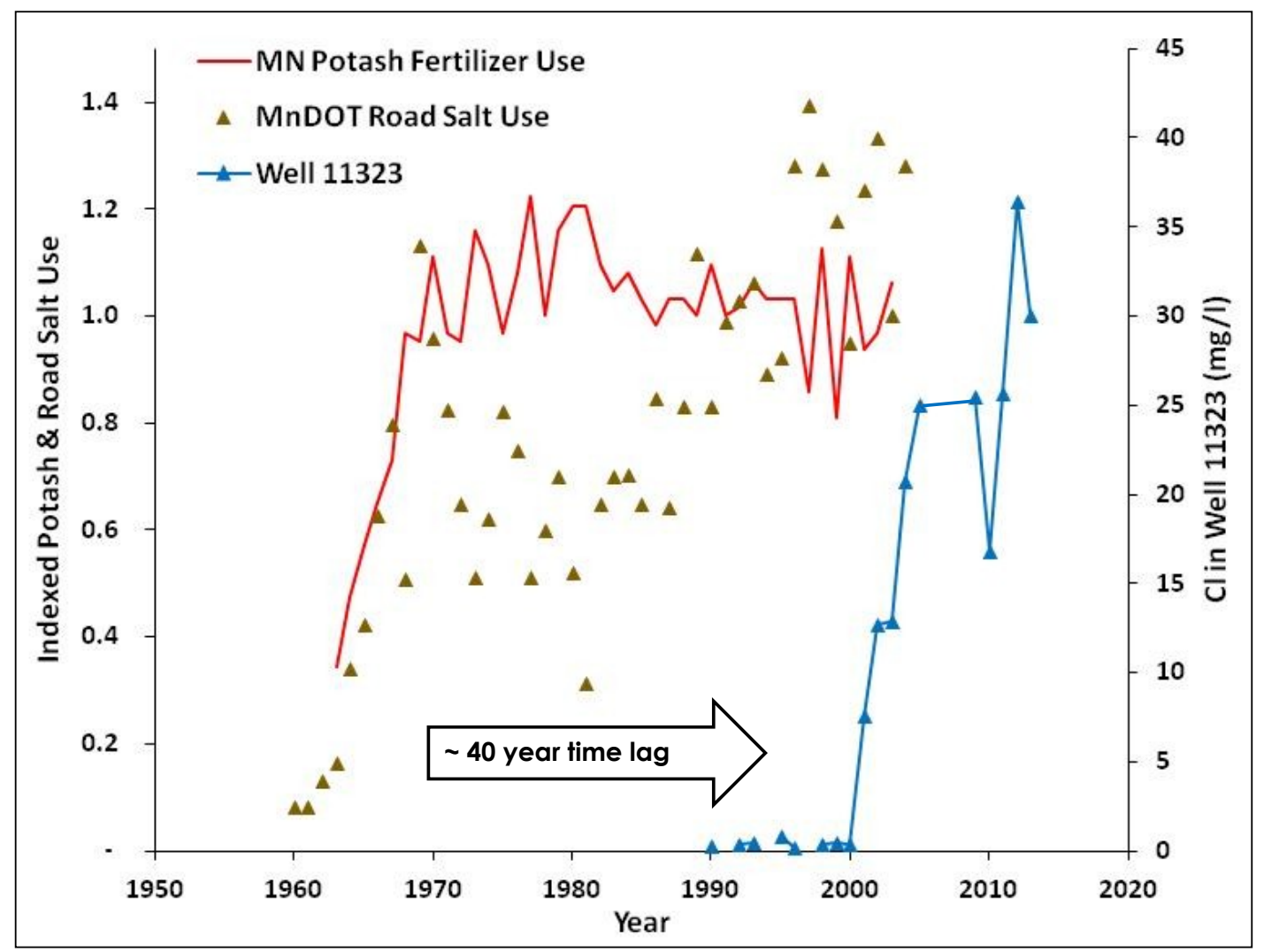

Figure 4. Minnesota Potash Fertilizer Use Trends and the Chloride Concentrations in Well 11323.

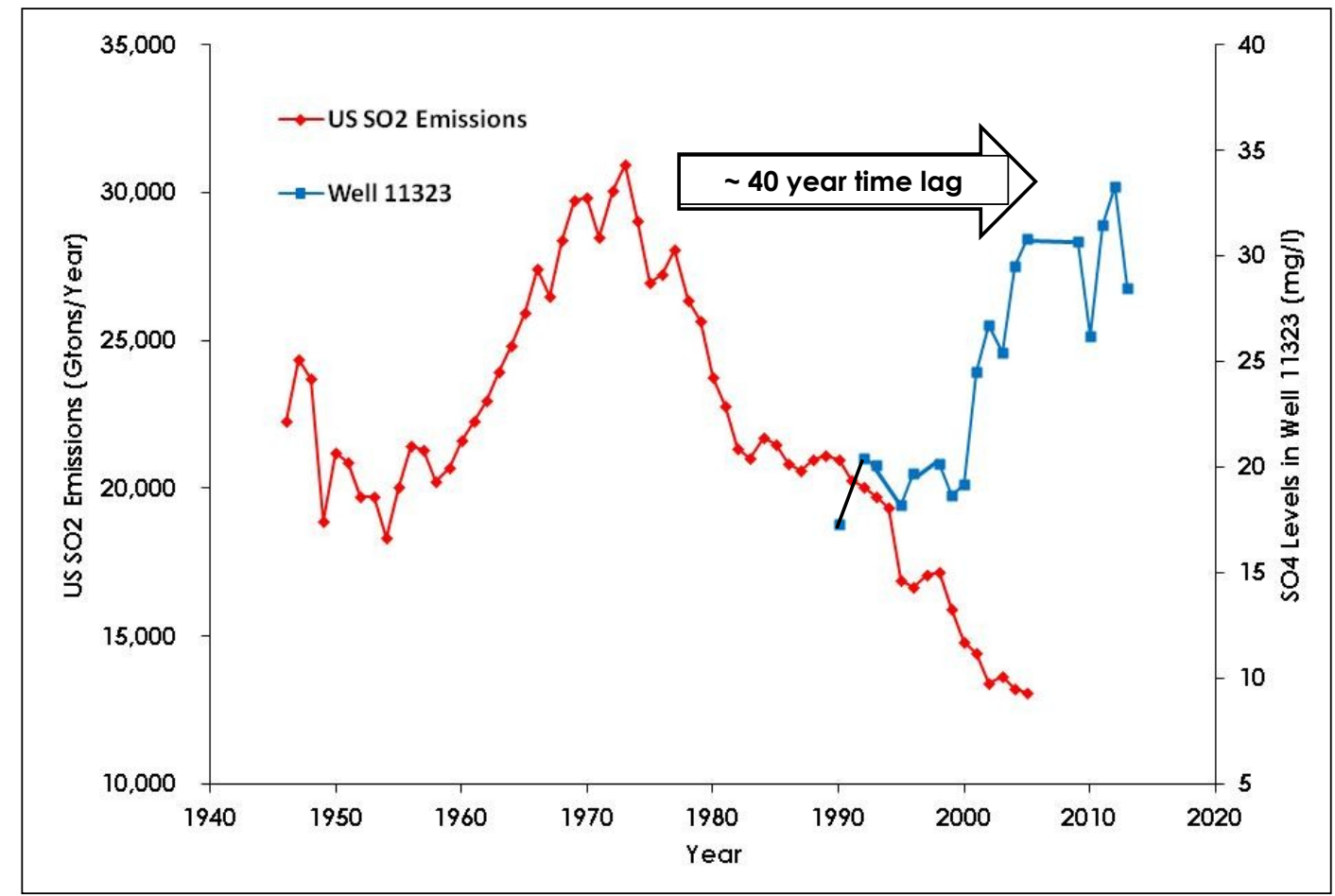

Figure 5. United States $\mathrm{SO}_{2}$ Emissions Trends and the Sulfate Concentrations in Well 11323. 


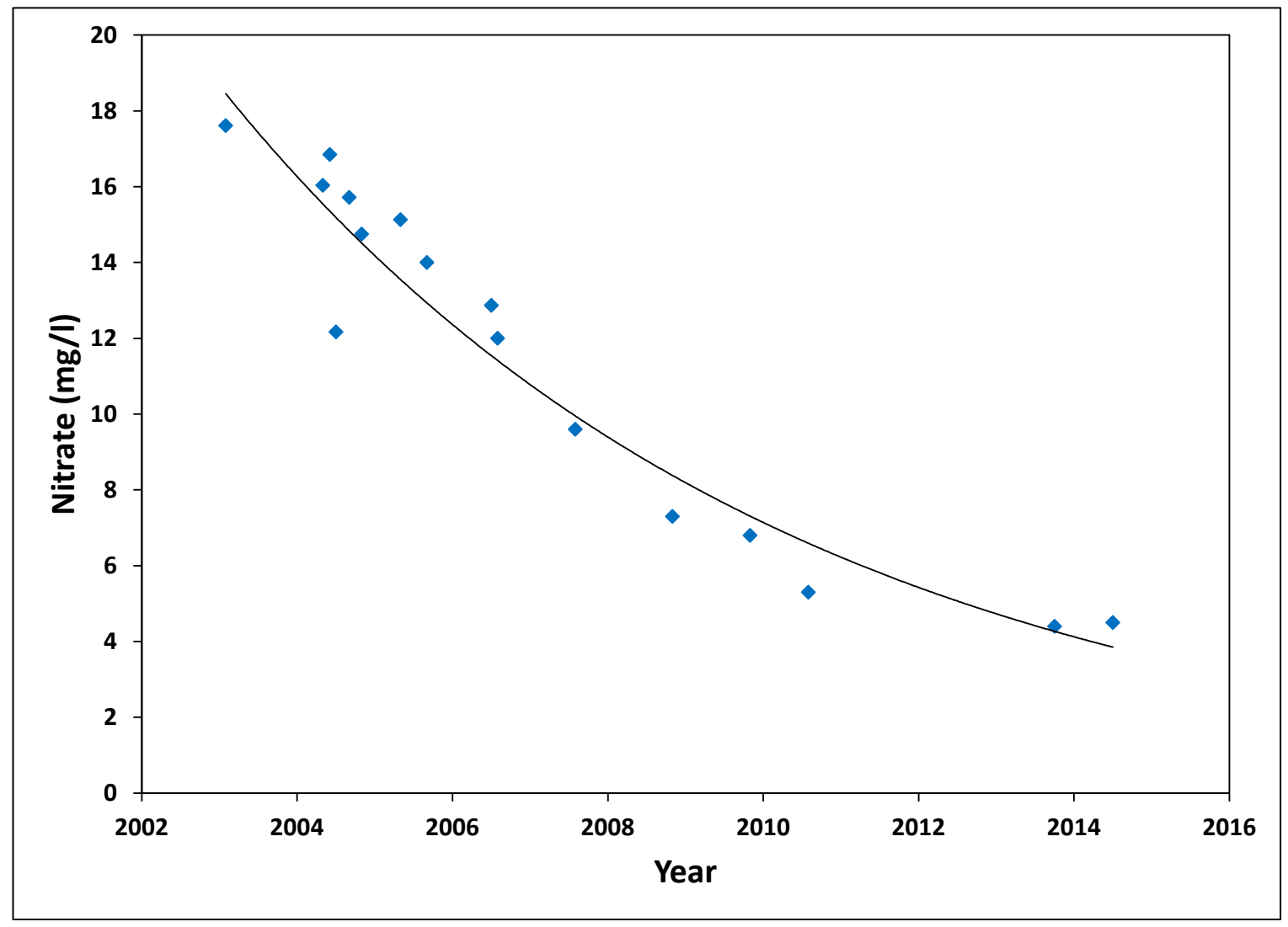

Figure 6. Downward Trend in Nitrate in Well 695881.

than with $\mathrm{Cl}(19 \%)$. Even with the longer $\mathrm{NO}_{3}$ record (44 years) there are fewer detections than $\mathrm{Cl}$ (26 years). The fraction of $\mathrm{NO}_{3}-\mathrm{N}$ non-detects in the trend well subset $\left[430 \mathrm{NO}_{3}-\mathrm{N}, \mathrm{Cl}, \mathrm{SO}_{4}\right.$ and $590 \mathrm{NO}_{3}-\mathrm{N}$ only] used in the trend analyses are consistent with the entire Olmsted County dataset of 7,048 records. Trends wells had 55\% non-detects versus $62 \%$ in the full Olmsted County dataset). There is a wider range in the $\mathrm{Cl}$ non-detects $(33 \%$ vs $19 \%$ ). The subset of wells used for trend analysis is more representative of the larger dataset for $\mathrm{NO}_{3}-\mathrm{N}$ than $\mathrm{Cl}$. There are fewer $\mathrm{NO}_{3}-\mathrm{N}$ trends, either up or down than is the case with either $\mathrm{Cl}$ or $\mathrm{SO}_{4}(11 \%$ vs $27 \%$ \& $29 \%$ respectively). Chloride and $\mathrm{SO}_{4}$ show similar numbers of upward trends ( 25 vs 23 ).

We calculate that more than 1,400 wells with 6 or more years of ion data are needed to be able to find one statistical logistic curve. It is thus fortunate that a couple of such curves were found in the Olmsted County dataset. Portions of logistic curves are easier to identify and several of these were also found.

The year categories in Table 3 are based on the ion source trend patterns presented in Figure 5. These cat-

\begin{tabular}{|l|c|c|c|}
\hline Trend Pattern & Nitrate & Chloride & Sulfate \\
\hline Background (ND) & 322 & 85 & 0 \\
\hline $\begin{array}{l}\text { Stable Above } \\
\text { Background (NT) }\end{array}$ & 204 & 239 & 304 \\
\hline Linear Up (UP) & 28 & 98 & 75 \\
\hline Linear Down (DN) & 16 & 9 & 19 \\
\hline Peaking (Q-) & 18 & 14 & 24 \\
\hline $\begin{array}{l}\text { Exponential Up or } \\
\text { Logistic (Q+) }\end{array}$ & 2 & 1 & 8 \\
\hline Total & 590 & 446 & 430 \\
\hline
\end{tabular}

Table 2. Olmsted County Wells by Trend Pattern.

egories reflect the differing trend patterns during these general periods. This allows the placement of wells into age brackets by trends for each ion. This provides a test for the calculated Intercept-Year and the consistency of age ranges for the other five trend patterns. 
Analysis of the assigned trend pattern for each well is shown in Table 3. Only wells with data for all three ions are represented. 164 of the wells (38\%) during their monitoring period are associated with water sources preceding 1960. 211 of the wells (49\%) are calculated to have water younger than 1970 based on their monitoring period.

For the 85 wells with upward trends for either $\mathrm{NO}_{3}-\mathrm{N}$ and/or $\mathrm{Cl}$, Intercept-Years were calculated. 75 of those wells $(88 \%)$ had their Intercept-Years in the predicted category in Table 3. When there is more scatter in the data or the projected Intercept-Year is further from the monitoring period, there is greater uncertainty in the Intercept-Year.

The age classification in Table 4 is based on the best fit of all three ions. There is some overlap in the age periods for the 430 wells due to multiple combinations of age trend patterns in Table 3.

\section{Ion trends for Dakota County Wells}

The Dakota Couonty well database consists of 76 wells monitored annually from 1999 to 2013. The monitoring period for individual wells in this database differs from that of the SEMWAL database. The SEMWAL database represents a larger number of wells and often with a longer monitoring record.

\begin{tabular}{|c|c|c|c|}
\hline Period & Nitrate & Chloride & Sulfate \\
\hline$<1960$ & ND & ND & NT or Quad + \\
\hline $1960 \mathrm{~s}$ & ND, NT or UP & ND or UP & UP \\
\hline $1970 \mathrm{~s}$ & ND, NT or UP & ND, NT or UP & NT or Quad- \\
\hline$>1980$ & ND, NT or UP & ND, NT or UP & Down \\
\hline
\end{tabular}

Table 3. Expected Well Trends Based on Source Trend Patterns. ND - either none detected or there is no ion loading source.

\begin{tabular}{|l|c|}
\hline \multicolumn{1}{|c|}{ Source Trend Pattern Periods } & $\#$ Wells \\
\hline Older than 1960 & 164 \\
\hline $1960-1970$ & 28 \\
\hline $1960-1980$ & 13 \\
\hline 1970 s & 4 \\
\hline Younger than 1970 & 186 \\
\hline Younger than 1980 & 21 \\
\hline Likely Land Use Change & 14 \\
\hline Total & 430 \\
\hline
\end{tabular}

Table 4. SEMWAL Wells Categorized by Matching Well Trend Pattern to Ion Source Trend Pattern Periods from Table 3.
Table 5 summarizes the results of trend analysis for 76 Dakota County wells from 1999 to 2013. Twenty- two (29\%) of the 76 Dakota County wells have changing $\mathrm{NO}_{3}-\mathrm{N}$ trend patterns, of these $72 \%$ are upward or recently peaking. Thirty-three (43\%) of the 76 have changing trend patterns for $\mathrm{Cl}$ with all but two upward or recently peaking. Thirty (39\%) of the 76 have changing trend patterns for $\mathrm{SO}_{4}, 25$ of these are up and five are down. Twenty-six (34\%) of the wells have trends for $\mathrm{Na}$ and only one is down. Fifteen of these 26 also have $\mathrm{Cl}$ trends and again only one is down (the same as for $\mathrm{Na}$ ).

\section{Comparison of Dakota and Olmsted Well Trends}

The Dakota dataset includes a smaller fraction of nondetections of both $\mathrm{NO}_{3}-\mathrm{N}(46 \%$ vs $55 \%)$ and $\mathrm{Cl}$ (19\% vs $22 \%$ ) when compared to the Olmsted data. In addition, there is a larger fraction of $\mathrm{NO}_{3}-\mathrm{N}(13 \%$ vs $5 \%)$ and $\mathrm{Cl}$ (37\% vs 22\%) linear up trends in Dakota County. The A Dakota data also includes $\mathrm{Na}$ which has a similar linear up trend pattern as $\mathrm{Cl}(37 \%$ vs $32 \%)$. The proportion of $\mathrm{SO}_{4}$ linear up and linear down trends vary less between the Dakota and Olmsted data sets - up trends (24\% vs $17 \%$ ) and down trends (5\% vs $4 \%$ ).

\section{Discussion}

This method has just two variables, ion source and the time lag between the source and ion level in extracted water over time. Unlike hydrologic models, it is not dependent on the hydrogeologic setting variables such as gradient, porosity, permeability, or any other flow variables. Knowledge of the ion source pattern at a regional scale allows an estimate of the time lag.

This method can be applied to a single or a large set of wells. The degree of consistency in predicted ages or age ranges based upon $\mathrm{NO}_{3}-\mathrm{N}, \mathrm{Cl}, \mathrm{Na}$, and $\mathrm{SO}_{4}$, suggest that any one of these anions could be used alone to predict water ages. However, using a combination of anions increases confidence in the results. Public wells with longer records and more frequent testing for a greater number of analytes would be particularly suitable.

\begin{tabular}{|l|c|c|c|c|}
\hline Trend Pattern & Nitrate & Chloride & Sodium & Sulfate \\
\hline Background & 35 & 17 & 0 & 0 \\
\hline Stable Above Background & 19 & 26 & 50 & 46 \\
\hline Linear Up & 10 & 28 & 24 & 18 \\
\hline Linear Down & 7 & 1 & 1 & 4 \\
\hline Peaking & 4 & 3 & 1 & 7 \\
\hline Exponential Up or Logistic & 1 & 1 & 0 & 1 \\
\hline Total & 76 & 76 & 76 & 76 \\
\hline
\end{tabular}

Table 5. Dakota County Wells by Trend Pattern. 
The $\mathrm{SO}_{2}$ loading peak in the mid-1970s provides a second marker for calculating a specific age (Figure 2). In addition, the apparent correlation between $\mathrm{SO}_{2}$ emissions and $\mathrm{SO}_{4}$ in Figure 2, and the availability of a much longer $\mathrm{SO}_{2}$ emissions record (1850-2014), suggests that $\mathrm{SO}_{4}$ will be useful in differentiating the age of wells with non-detectable $\mathrm{NO}_{3}-\mathrm{N}$ and $\mathrm{Cl}$. Significant decreases in $\mathrm{SO}_{2}$ loadings during historic recessions might be particularly useful age markers.

The SEMWAL database contains an additional 34,000 $\mathrm{NO}_{3}-\mathrm{N}, \mathrm{Cl}$, and $\mathrm{SO}_{4}$ records for wells in counties adjoining Olmsted. That data could be used to complete similar studies. Because these counties have historically applied a less rigorous $\mathrm{NO}_{3}-\mathrm{N}$ standard for well development, they likely would have more wells with trends useful for calculating the Intercept-Year.

Using the well from Figures $1-4$ as a case study illustrates the potential value of this analysis for individual wells. Well 11323 serves a bar and grill that is licensed by the Olmsted County Health Department. Based on the estimated 40-year age of the water, it is not likely that the well will present a health hazard based on bacteria or viruses since those organisms would no longer be viable. The decline in the rate of increase in $\mathrm{NO}_{3}-\mathrm{N}$ and $\mathrm{Cl}$ concentrations in the well in recent years corresponds with the smaller rate increases in fertilizer and road salt use. The $\mathrm{Cl}: \mathrm{NO}_{3}-\mathrm{N}$ ratio is about 4:1 suggesting that over half of the $\mathrm{Cl}$ is from road salt or softener salt. The current $\mathrm{NO}_{3}$ level is about $50 \%$ of the drinking water standard $(10 \mathrm{mg} / \mathrm{l})$ and $\mathrm{Cl}$ about $10 \%$ of the secondary standard ( $250 \mathrm{mg} / \mathrm{l})$. Given the 40 -year historical relationship between loading rates and $\mathrm{NO}_{3}-\mathrm{N}$ and $\mathrm{Cl}$ concentrations in the well, the well is not likely to exceed either standard in the near future. Considering the water age, this would not be a useful monitoring well for best management practices being implemented today. If in the future monitoring is expanded beyond basic parameters they should include both agricultural as well as non-agricultural pollutants, particularly those used in earlier decades.

\section{References}

Dahl D, Bursch W, and Rathjen R. 1970. University of Minnesota Agricultural Experiment Station, Minnesota Fertilizer Industry Trends and Prospects, Miscellaneous Report 76.

Environmental Management for Dakota County. Dakota County Ambient Groundwater Quality Study (AGQS): 2009-2014. 2015. Dakota.mn.us; [updated 2013 November 5; cited 2015 March 13]. Available from: http://www.co.dakota.mn.us/ Environment/LandConservation/FNAP.

Environmental Protection Agency (EPA)-US. 2010.
"Fertilizer Applied for Agricultural Purposes." [updated 2009 November 19]. Available at: http:// cfpub.epa.gov/roe/indicator.cfm?i=55.

Green CT, Bekins BA. 2010. Sustainability of Natural Attenuation of Nitrate in Agricultural Aquifers, USGS Fact Sheet 2010-377.

Helsel D. 2012. Statistics for Censored Environmental Data using Mintab@ and R. Hoboken (NJ): John Wiley \& Sons, Inc. p. 258-264.

Helsel D, Hirsch R. 2002. Statistical Methods in Water Resources Techniques of Water Resources Investigations, Book 4, chapter A3. U.S. Geological Survey. p. 321-353.

Kelly TD, Matos GR, comps. 2013. Historical statistics for mineral and material commodities in the United States: U.S. Geological Survey Data Series 140, [updated 2014 April 09; cited 2015 March 13]. Available from: http://minerals.usgs.gov/minerals/ pubs/historical-statistics/.

McMahon PB, Cowdery TK, Chapelle FH, Jurgens BC. 2009. Redox conditions in selected principal aquifers of the United States: U.S. Geological Survey Fact Sheet 2009-3041. [updated 2013 January 09; cited 2015 March 13]. Available from: http://pubs.usgs.gov/fs/2009/3041/pdf/FS09-3041. pdf.

Minnesota Department of Agriculture (MDA). Minnesota Nitrogen Fertilizer Management Plan, Public Comment Draft. 2013. Pesticide and Fertilizer Management Division. Available from: http://www.mda.state.mn.us/nfmp.

Minnesota Department of Transportation (MNDOT). 2014. "Trends in Road Salt Use". Available from: http://purl.umn.edu/151669.

Minnesota Department of Transportation (MNDOT). 2014. "Study of Environmental Effects of DeIcing Salt on Water Quality in the Twin Cities Metropolitan Area, Minnesota" St. Paul (MN): University of Minnesota. [Cited 2015 March 13]. Available from: http://purl.umn.edu/151669.

Minnesota Pollution Control Agency (MPCA). 2013. Nitrogen in Minnesota Surface Waters: conditions, trends, sources, and reductions. Available from: www.pca.state.mn.us, www.pca.state. mn.us/6fwc9hw.

Minnesota Pollution Control Agency (MPCA). 2013. "Condition of Minnesota's groundwater, 20072011." Document number wa-am1-06, p. 1521. Available from http://www.pca.state.mn.us/ index.php/water/water-types-and-programs/ groundwater/index.html

Minnesota Pollution Control Agency (MPCA), Minnesota Department of Agriculture (MDA). 
1991. "Nitrogen in Minnesota Groundwater, part one, Existing Conditions, Trends, and Fate" p. b1b5.

Montgomery B. 2012. Nitrates in Groundwater-Filtering Out the Facts. MN Agriculture and Nitrates Forum; [updated 2012 July 25; cited 2015 March 13]. Available from: http://www.mawrc.org/downloads/ Montgomery-Nitrates_in_Groundwater.pdf.

Robertson WD, Cherry J, Schiff SI. 1989. "Atmospheric Sulfur Deposition 1950-1985 inferred from Sulfate in Groundwater", Water Resources Research 25 (6): 1111-1123.

Smith SJ, Conception, EAndres R, Lurz J. 2004. "Historical Sulfur Dioxide Emissions 1850-2000: Methods and Results" Pacific Northwest National Laboratory, PNNL-14537.

Smith SJ, Van Aardenne J, Klimont Z, Andres RJ, Volke A, Delgado Arias S. 2011. Anthropogenic sulfur dioxide emissions: 1850-2005. Atmos. Chem. Phys 11: 1101-1116.

Southeast Minnesota Water Analysis Laboratory (SEMWAL). 2015. Olmsted County Minnesota. Available from: www.co.olmsted.mn.us/waterlab.

United States Department of Agriculture (USDA) National Agricultural statistics Service (NASS) and Association of American PLANT Food Control Officials(AAPFCO)/The Fertilizer Institute(TFI). 2014. Estimates of plant nutrient use for crops. Available at Http//www. nass. gov/ 